\title{
Two Brothers with Atypical UNC13D-Related Hemophagocytic Lymphohistiocytosis Characterized by Massive Lung and Brain Involvement
}

\section{OPEN ACCESS}

Edited by: Waleed Al-Herz,

Kuwait University, Kuwait

Reviewed by:

Takahiro Yasumi,

Kyoto University, Japan

Anete S. Grumach,

Faculty of Medicine ABC, Brazil

*Correspondence:

Claudio Pignata

pignata@unina.it

tThese authors have contributed equally to this work.

Specialty section:

This article was submitted to Primary Immunodeficiencies,

a section of the journal

Frontiers in Immunology

Received: 17 October 2017 Accepted: 11 December 2017 Published: 21 December 2017

Citation:

Giardino G, De Luca M, Cirillo E, Palma $P$, Romano $R$, Valeriani $M$, Papetti L, Saunders C, Cancrini C and Pignata C (2017) Two Brothers

with Atypical UNC13D-Related Hemophagocytic

Lymphohistiocytosis

Characterized by Massive Lung and Brain Involvement.

Front. Immunol. 8:1892. doi: 10.3389/fimmu.2017.01892

\author{
Giuliana Giardino', Maia De Luca², Emilia Cirillo', Paolo Palma³, Roberta Romano', \\ Massimiliano Valeriani ${ }^{4}$, Laura Papetti ${ }^{4}$, Carol Saunders ${ }^{5,6,7}$, Caterina Cancrini ${ }^{2,8 t}$ \\ and Claudio Pignata ${ }^{1 * t}$
}

\begin{abstract}
'Department of Translational Medical Sciences, Federico II University of Naples, Naples, Italy, ${ }^{2}$ Unit of Immune and Infectious Diseases, University Department of Pediatrics (DPUO), Bambino Gesù Children's Hospital, Rome, Italy, ${ }^{3}$ Research Unit in Congenital and Perinatal Infection, Unit of Immune and Infectious Diseases, University Department of Pediatrics (DPUO), Bambino Gesù Children's Hospital, Rome, Italy, ${ }^{4}$ Neurology Unit, Bambino Gesù Children's Hospital, Rome, Italy, ${ }^{5}$ Center for Pediatric Genomic Medicine, Children's Mercy-Kansas City, Kansas City, MO, United States, ${ }^{6}$ School of Medicine, University of Missouri-Kansas City, Kansas City, MO, United States, ${ }^{7}$ Department of Pathology, Children's Mercy-Kansas City, Kansas City, MO, United States, ${ }^{8}$ Department of Systems Medicine, University of Rome Tor Vergata, Rome, Italy
\end{abstract}

Hemophagocytic lymphohistiocytosis $(H L H)$ is a potentially fatal hyperinflammatory condition. Variants in different genes have been associated with the familial forms of the syndrome (FHL), usually presenting within the first 2 years of life. Due to increasing awareness of the signs and symptoms of HLH and a better understanding of the genetic basis of the disease, FHL has been increasingly diagnosed in patients presenting beyond infancy. Here, we report on two brothers with atypical, late-onset HLH in which whole exome sequencing revealed a homozygous pathogenic UNC13D variant. In the first brother, the clinical phenotype was dominated by a massive lung involvement. In the second brother a progressive neurological deterioration was observed. In both cases, the clinical manifestations at symptom onset were misleading, making the diagnosis difficult to achieve. This report expands the spectrum of clinical presentations of FLH3. Moreover, it highlights the importance to warn clinicians to keep a high level of suspicion in patients presenting with fever, cytopenia, splenomegaly of unknown origin, and unresponsiveness to conventional treatment even beyond early childhood. Moreover, this report emphasizes that insidious neurologic symptoms may represent the initial or sole presenting sign of $\mathrm{FHL}$, even in the absence of peripheral signs of activation.

Keywords: UNC13D, FHL3, atypical FHL, CNS-HLH, extracorporeal membrane oxygenation

\section{INTRODUCTION}

Hemophagocytic lymphohistiocytosis (HLH) is a potentially fatal hyperinflammatory condition characterized by prolonged and unexplained fever, unresponsiveness to conventional treatment, hepatosplenomegaly, cytopenia, hypertriglyceridemia, and hypofibrinogenemia $(1,2)$. Variants in four different genes have been associated with the familial forms of the syndrome (FHL). FHL-2 is due to variations in the PRF1 gene, encoding perforin 1, implicated in target cell lysis (3). UNC13D 
encoding MUNC13-4, STX11 encoding SYNTAXIN11, and STXBP2 encoding MUNC18-2 are implicated in the trafficking and exocytosis of lytic granules, and mediate the release at the cell surface of perforin 1 and other effector molecules implicated in cytotoxicity (4-7). The impairment of the cytotoxic activity may lead to uncontrolled activation of cytotoxic $\mathrm{T}$ cells and macrophages, which finally result in a hyperinflammation, T-cell, and macrophage infiltration of various organs including bone marrow, liver, and the central nervous system (8).

FHL usually presents within the first 2 years of life (9). However, the increasing awareness of the signs and symptoms of HLH and the better comprehension of the genetic basis of the disease allow the identification of FHL in patients presenting beyond infancy and sometimes before the development of the HLH (10). Atypical presentations have been reported in adolescents and even in adults, characterized by milder and often recurrent HLH episodes and prolonged survival in the absence of hematopoietic stem cell transplantation (HSCT), unusual in patients with the typical disease. Here, we report on two brothers with atypical, late-onset HLH in which whole exome sequencing (WES) revealed a homozygous pathogenic UNC13D variant. In both cases, the clinical manifestations at symptom onset were misleading, making the diagnosis difficult to achieve.

\section{CASE REPORT}

Written informed consent was obtained from the parents for the publication of both the cases. The patients were dizygotic twins born preterm (33 weeks) following conception by in vitro fertilization, yielding a triplet pregnancy complicated by in utero death of the third fetus. Parents were not consanguineous and familial history was unremarkable, apart from a history of recurrent abortions in the mother. At the age of 6.2 years, after an uneventful childhood, the first brother developed fever resistant to antibiotics and severe, rapidly progressive dyspnea, requiring the admission to a pediatric intensive care unit for mechanical ventilation. The rapid progression of such a severe lung involvement raised the suspicion of a primary immunodeficiency (11). Clinical examination revealed splenomegaly and macular truncal rash. Laboratory examinations revealed trilineage cytopenia, hypertriglyceridemia, hypofibrinogenemia, and hyperferritinemia (Table 1). The analysis of the bone marrow aspirate revealed hypocellularity, but lymphocytes and histiocytes infiltration and hemophagocytosis were not observed. Lung $\mathrm{Rx}$ and CT scan revealed massive bilateral pulmonary consolidations with alveolar involvement, only sparing the apical lobes (Figures 1A-C). Klebsiella pneumoniae and Candida albicans were isolated from the bronchial aspirate while the pleural fluid culture was negative. Nasal, pharyngeal and rectal swab, urine culture, mannan, galactomannan and PCR for $H S V 1 / 2$, Parvovirus B19, HHV8, HHV6, CMV, EBV, and other respiratory viruses in the blood and bronchial aspirate were negative. Cytological examination of the pleural fluid showed an increase of the protein levels and of the leukocytes, in particular lymphocytes. Basal immunological examination revealed hypogammaglobulinemia (IgG $315 \mathrm{mg} / \mathrm{dL}$, IgA 46 mg/dL, IgM $58 \mathrm{mg} /$ $\mathrm{dL}$ ) with normal production of specific antibodies and a slight
TABLE 1 | Comparison of clinical and laboratory markers in the two twins carrying the same UNC13D mutation.

\begin{tabular}{|c|c|c|}
\hline & Patient 1 & Patient 2 \\
\hline UNC13D mutation & $\begin{array}{l}\text { Homozygous } \\
\text { 1847A }>\mathrm{G}\end{array}$ & Homozygous 1847A>G \\
\hline Age at onset & 6.2 years & 3 years \\
\hline Symptoms at the onset & $\begin{array}{l}\text { Fever and severe } \\
\text { dyspnea }\end{array}$ & $\begin{array}{l}\text { Pervasive developmental } \\
\text { disorder }\end{array}$ \\
\hline Fever & Yes & No \\
\hline Splenomegaly & Yes & Yes \\
\hline CNS involvement & No & Yes \\
\hline Lung involvement & $\begin{array}{l}\text { Massive bilateral } \\
\text { consolidations }\end{array}$ & $\begin{array}{l}\text { Signs of pulmonary } \\
\text { hypertension }\end{array}$ \\
\hline WBC (cells/mm³) & 800 & 7,750 \\
\hline Neutrophil count (cells/mm³) & 430 & 5,450 \\
\hline Lymphocyte count (cells/mm³) & 320 & 1,880 \\
\hline Platelet count (cells/mm³) & 27,000 & 241,000 \\
\hline Hemoglobin levels (g/dL) & 7.8 & 14.9 \\
\hline Fibrinogen (mg/dL) & 89 & n.a. \\
\hline Triglycerides (mg/dL) & 1,556 & 110 \\
\hline Ferritin $(\mathrm{ng} / \mathrm{mL})$ & 2,550 & 84 \\
\hline Albumin (gr/dL) & 2.4 & 5 \\
\hline $\operatorname{lgG} / \lg A / \lg M(\mathrm{mg} / \mathrm{dL})$ & $315 / 46 / 58$ & $487 / 45 / 120$ \\
\hline $\operatorname{lgE}(I U / \mathrm{mL})$ & 249 & n.a. \\
\hline CD3+ \% (cells $\left./ \mathrm{mm}^{3}\right)$ & $57 \%(182)$ & $77.5 \%$ \\
\hline CD4+ \% (cells/mm³) & $34 \%(109)$ & $33 \%$ \\
\hline CD8+ \% (cells/mm³) & $13 \%(42)$ & $33.2 \%$ \\
\hline CD19+ \% (cells $\left./ \mathrm{mm}^{3}\right)$ & $8 \%(26)$ & $21 \%$ \\
\hline CD16+ CD56+ \% (cells/mm³) & $22 \%(70)$ & $1.5 \%$ \\
\hline CD4+ CD45RA+ \% (cells/mm³) & n.a. & $6.6 \%$ \\
\hline CD4+ CD45RO+ \% (cells $\left./ \mathrm{mm}^{3}\right)$ & n.a. & $26.4 \%$ \\
\hline CD8+ CD45RA+ & n.a. & $14.9 \%$ \\
\hline CD8+ CD45RO+ & n.a. & $18.3 \%$ \\
\hline CD3+ HLADR+ & $27 \%$ & n.a. \\
\hline Granule release assay & n.a. & Absent degranulation \\
\hline Perforin expression & n.a. & Normal \\
\hline Bone marrow aspirate & Hypocellularity & Lymphohistiocytic infiltration \\
\hline
\end{tabular}

CNS, central nervous system; WBC, white blood cells; n.a., not available.

increase of IgE levels (249 IU/mL). A marked lymphopenia was observed, despite normal T, B, and NK cells percentages, apart from an increase of the CD3+ HLADR+ cells (Table 1). WES was performed due to suspicion of a CID with secondary HLH. Treatment with intravenous immunoglobulins, antibiotics, and antifungals was started. Venous extracorporeal membrane oxygenation (ECMO) was initiated due to the development of bilateral massive pneumothorax, but unfortunately the patient died of cardiopulmonary collapse.

The second brother developed a pervasive developmental disorder at the age of 3 years. By age 5 , his neurological condition deteriorated with the development of asthenia, ataxia, and nystagmus, facilitating a neurological evaluation. Brain MRI revealed areas of demyelination enhanced by contrast agent, involving pons, cerebellar peduncles, cerebellum, and white matter of the left temporal lobe (Figures 1D,E). CSF evaluation revealed pleocytosis and oligoclonal bands. Based on the radiological findings and favorable response to steroid treatment, a diagnosis of Chronic Lymphocytic Inflammation with Pontine Perivascular Enhancement Responsive to Steroids was suspected and the patient was started on Azathioprine. However, clinical and radiological findings deteriorated despite the immunosuppressive treatment 


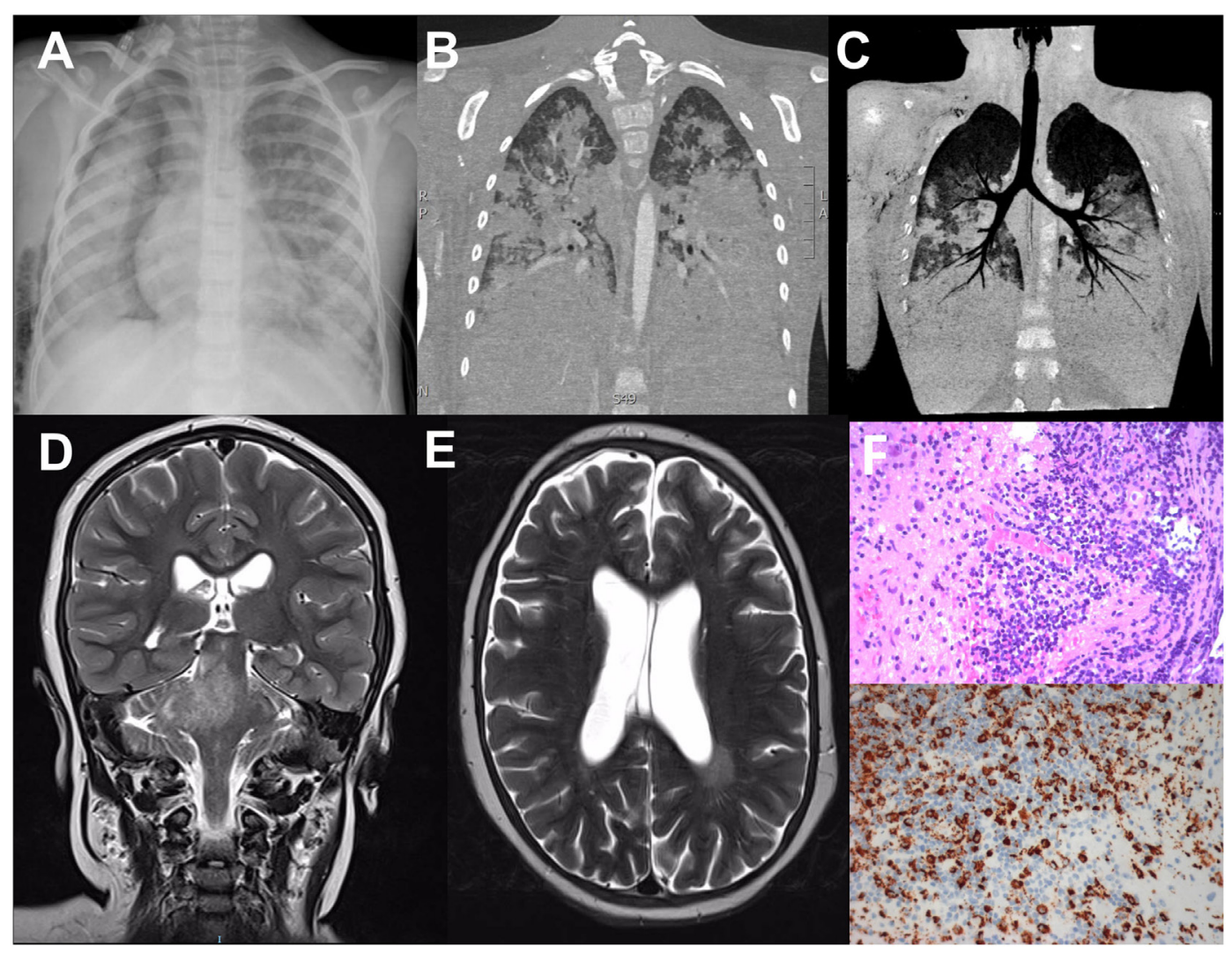

FIGURE 1 | Radiological findings in the dizygotic twins homozygous for 1847A>G (p.Glu616Gly) in UNC13D. (A) Thoracic Rx of the patient 1; broad area of opacity involving the right mediobasal lobe and the left basal lobe, with bilateral hilar and perihilar infiltration. (B,C) Pulmonary CT scan of the patient 1; massive bilateral pulmonary consolidations with alveolar involvement, only sparing the apical lobes. (D,E) Brain MRI scan of the patient 2; T2w image with hyperintense signal in the left periventricular region, in pons, right cerebellar peduncles, and right cerebellar hemisphere. (F) Hematoxylin-eosin staining of the brain biopsy showing lymphohistiocytic perivascular and intraparenchymal inflammatory infiltrate (upper panel); immunohistochemical staining for the histiocytic marker CD68 (lower panel).

and a brain biopsy was performed showing a lymphohistiocytic perivascular and intraparenchymal inflammatory infiltrate (Figure 1F). A CNS-HLH was suspected. Peripheral markers of activation were evaluated and found to be normal (Table 1). Splenomegaly and bone marrow lymphohistiocytic infiltration were detected. Immunological studies revealed normal IgG, IgA, and IgM levels and slightly increased CD3+ cells, mainly showing a memory phenotype, absent degranulation of the NK cells after the stimulus with K562 cells, normal perforin expression, suggesting a diagnosis of HLH (Table 1).

In the first brother, WES revealed a homozygous pathogenic UNC13D variant, 1847A $>$ G (p.Glu616Gly). This variant has been previously reported in affected individuals, and functionally demonstrated to result in deranged splicing of the gene $(12,13)$. It is absent from population databases. The second twin was genotyped for the variant by Sanger sequencing, revealing homozygosity for the same $U N C 13 D$ variant. The parents were both heterozygous. A diagnosis of isolated CNSHLH was made, and the patient was started on the HLH-2004 protocol. The patient unfortunately died of transplant-related complications.

\section{DISCUSSION}

Hemophagocytic lymphohistiocytosis represents the clinical and immunological manifestation of several diseases including FHL, characterized by a well-known pathogenic mechanism and a large number of disorders in which pathogenesis is still poorly understood. Indeed, HLH has been found in association with inborn errors of the metabolism (14-16), autoimmune disease (17), congenital immunodeficiencies, such as chronic granulomatous disease (18), DiGeorge syndrome (19), severe combined immunodeficiency (20), and X-linked agammaglobulinemia $(21,22)$, and other disorders (23-25). These last cases, described as "secondary" HLH, usually present in older children. More recently, the increasing awareness of the presenting signs of the disease and the development of new tools for the diagnosis of these conditions have made possible the identification also in patients presenting later in life with atypical symptoms (26). Considering the similarities between atypical FHL and secondary $\mathrm{HLH}$, it can be difficult in some cases to achieve a rapid diagnosis. Moreover, in many cases of atypical FHL, the peripheral signs of HLH may be completely absent, making the diagnosis even 
more difficult to achieve. In a recent paper, Gray et al reported on a case of late-onset FHL3 in which the clinical presentation was characterized by growth arrest, inflammatory arachnoiditis, and dysgammaglobulinemia, without any signs of HLH (10). Similarly, the hypomorphic A91V variation has been recently described in association with atypical late-onset HLH in a patient with neuromyelitis optica (27).

In this report, we describe two male dizygotic twins with atypical FHL3 $(12,13,28)$. In both patients, the onset was delayed compared to the median age of 4.1 months reported in a wide cohort of FHL3 patients (13). Missense variants in UNC13D are associated with a later onset as compared with loss of function variants and median age at the diagnosis was 117.5 months in four patients with homozygous c.1847A $>\mathrm{G}$ (13). The two brothers presented with very different clinical manifestations. In the first brother the clinical picture was dominated by a massive lung involvement and laboratory features suggested a secondary HLH in the context of a CID (24). WES failed to detect mutations other than UNC13D. However, even though primary immunodeficiencies have been traditionally considered as monogenic disorders, in the recent years high throughput sequencing techniques have highlighted that atypical phenotypes may be explained by the coexistence of multiple mutations (29-33). Since WES may not be able to detect large deletion/insertion and deep intronic mutations, we cannot exclude that a second mutation may have had a role in shaping such a complex clinical phenotype. On the other hand, even though immunological alterations are not usually found in patients with typical FHL, recent evidence suggests that different immunological alterations including antibody deficiency, low B-cell numbers, reduced percentage of marginal-zone like and class-switched memory B cells, and susceptibility to bacterial sinopulmonary infections may be detected in patients with different forms of FHL (34). In some cases, hypogammaglobulinemia and defects of specific antibodies developed after recurrent mild episodes of HLH (34). Interestingly, the immunological alterations are not usually found in patients with typical FHL, suggesting that in atypical forms a silent chronic T cell activation may impair the B cell development leading to the development of hypogammaglobulinemia (34). For this reason, the association of a clinical picture of common variable immunodeficiency/CID, with splenomegaly, cytopenia, and episodes of unexplained fever should address the diagnosis also toward atypical FHL (34).

Lung involvement is not well characterized in HLH, especially in pediatric patients and guidelines on the treatment of these conditions are also lacking (35). In a cohort of adult patients, lung involvement, due to lymphocytic infiltration or infection, was reported in about $54 \%$ of cases and associated with a worse prognosis (36). However, adult HLH may have a different pathogenesis compared to children affected with FHL. In the patient described, Klebsiella pneumoniae and Candida albicans may have played a role in triggering the lung involvement and, moreover, the hypogammaglobulinemia along with the marked lymphopenia may have had a role in the rapid deterioration of the clinical conditions. However, it should be noted that five out of eight HLH diagnostic criteria were present at the diagnosis (fever, splenomegalia, trilineage cytopenia, hyperferritinemia, hypofibrinogenemia/ hypertriglyceridemia), suggesting that HLH also had a role in shaping the clinical picture. Moreover, the patient did not show any sign of improvement despite 3 months of intravenous treatment with immunoglobulins, different antifungals, and antibiotics, suggesting an inflammatory more than infectious condition. Even though lung biopsy was not performed in our patients, all cultures, including pleural fluid were negative, with pleural fluid showing increased levels of proteins and lymphocytes, suggesting lung infiltration by activated lymphocytes and histiocytes. In our patient, ECMO was initiated due to the development of bilateral massive pneumothorax. However, in a recent study on a small cohort of patients, survival of pediatric HLH patients on ECMO was worse than patients without HLH on ECMO (37). It should be noted that the severity of the clinical manifestations and the high mortality related to the lung involvement may themselves lead to a reduced estimation of the incidence of the lung involvement in FHL, since the patient may die without receiving a genetic diagnosis.

The second brother presented at the age of 3 years with signs of a pervasive developmental disorder. His neurological conditions deteriorated progressively over a very long period. While lung infiltration is an unusual presentation of FHL $(12,13)$, neurologic signs are present in about $2 / 3$ of the patients with FLH at the onset and may also develop later in the course of the disease $(38,39)$. Common neurological manifestations include irritability, seizures, bulging fontanel in infants, neck stiffness, hypotonia, and hypertonia $(9,40,41)$. Other less common signs include nonspecific signs of increased intracranial pressure, cranial nerve palsy, ataxia, hemiplegia, quadriplegia, blindness, and coma $(9,40,41)$. CSF examination usually shows elevated protein, increased number of mononuclear cells, and occasionally hemophagocytosis $(9,40,41)$. Typical radiologic findings include demyelination or impaired myelination, gray and white matter multifocal inflammation mimicking neuroinflammatory disorders including multiple sclerosis and acute disseminated encephalomyelitis $(41,42)$. FHL3 patients seem to be even more prone to develop CNS involvement. In a recent study, $60 \%$ of the patients with FHL3 showed a CNS involvement compared with the $32 \%$ in patients with FHL2 (13). Moreover, the variant identified in these twins has been frequently associated with CNS involvement (13). Of note, in our patient, more typical clinical neurological manifestations associated with $\mathrm{HLH}$, including demyelination, ataxia, and cerebral palsy (43), were preceded by a pervasive developmental disorder, suggesting a very slow and insidious process which delayed the diagnosis. Moreover, the patient never showed any sign of systemic HLH. Previous evidence suggest that primary HLH may also represent the underlying cause of unknown CNS inflammation even in the absence of overt clinical signs of HLH, suggesting that FHL should be included in the differential diagnosis of unclassified progressive neuroinflammatory disease (44-50). T and NK cell degranulation assays and the evaluation of the expression of intracellular perforin can be used for the prompt identification of such patients, allowing a targeted treatment (51). Corticosteroids, etoposide, cyclosporine A, commonly used for the treatment of systemic HLH, along with intrathecal methotrexate and corticosteroids represent the standard, first-line therapeutic approach also for 
the treatment of CNS-HLH $(1,9,38)$. Antithymocyte globulin has also been used, in association with steroids, cyclosporin A, and intrathecal methotrexate injection to achieve remission in HLH (52). However, the efficacy of this association on CNS is comparable to the HLH-94 protocol $(38,52)$. HSCT also represents an important tool for the treatment of CNS-HLH especially in patients with familial forms, or with severe, persistent or reactivated HLH (38). Recently, novel therapeutic approaches are emerging as effective in the treatment of the refractory and complicated HLH even though many of these are still considered as second line or salvage experimental treatments. Among these, alemtuzumab has shown promising results in the treatment of the refractory $\mathrm{HLH}$ even though its effectiveness in the treatment of refractory CNS-HLH has not been clarified yet (53). Based on encouraging preclinical data from animal model, a clinical trial (NCT01818492) is currently ongoing to evaluate the efficacy of anti-IFN $\gamma$ monoclonal antibody NI-0501 in the treatment of refractory HLH. Finally, the JAK1/2 inhibitor ruxolitinib has been recently shown to be effective in reducing the CNS involvement in a Rab27a $\mathrm{a}^{-1-}$ mouse model (54).

\section{CONCLUDING REMARKS}

In conclusion, this report expands the spectrum of clinical presentations of FLH3. It is important to warn clinicians to keep a high level of suspicion in patients presenting with fever, cytopenia, splenomegaly of unknown origin, and unresponsiveness

\section{REFERENCES}

1. Henter JI, Horne A, Arico M, Egeler RM, Filipovich AH, Imashuku S, et al. HLH-2004: diagnostic and therapeutic guidelines for hemophagocytic lymphohistiocytosis. Pediatr Blood Cancer (2007) 48(2):124-31. doi:10.1002/ pbc. 21039

2. Giardino G, Veropalumbo C, Ruggiero G, Naddei R, Rubino V, Udhayachandran A, et al. Phenotypic characterization and outcome of paediatric patients affected with haemophagocytic syndrome of unknown genetic cause. Br J Haematol (2013) 162(5):713-7. doi:10.1111/bjh.12421

3. Stepp SE, Dufourcq-Lagelouse R, Deist FL, Bhawan S, Certain S, Mathew PA, et al. Perforin gene defects in familial hemophagocytic lymphohistiocytosis. Science (1999) 286(5446):1957-9. doi:10.1126/science.286.5446.1957

4. zur Stadt U, Schmidt S, Kasper B, Beutel K, Diler AS, Henter JI, et al. Linkage of familial hemophagocytic lymphohistiocytosis (FHL) type-4 to chromosome $6 \mathrm{q} 24$ and identification of mutations in syntaxin 11. Hum Mol Genet (2005) 14(6):827-34. doi:10.1093/hmg/ddi076

5. zur Stadt U, Rohr J, Seifert W, Koch F, Grieve S, Pagel J, et al. Familial hemophagocytic lymphohistiocytosis type 5 (FHL-5) is caused by mutations in Munc18-2 and impaired binding to syntaxin 11. Am J Hum Genet (2009) 85(4):482-92. doi:10.1016/j.ajhg.2009.09.005

6. Cote M, Menager MM, Burgess A, Mahlaoui N, Picard C, Schaffner C, et al. Munc18-2 deficiency causes familial hemophagocytic lymphohistiocytosis type 5 and impairs cytotoxic granule exocytosis in patient NK cells. J Clin Invest (2009) 119(12):3765-73. doi:10.1172/jci40732

7. Feldmann J, Callebaut I, Raposo G, Certain S, Bacq D, Dumont C, et al. Munc13-4 is essential for cytolytic granules fusion and is mutated in a form of familial hemophagocytic lymphohistiocytosis (FHL3). Cell (2003) 115(4):461-73. doi:10.1016/S0092-8674(03)00855-9

8. Fischer A, Latour S, de Saint Basile G. Genetic defects affecting lymphocyte cytotoxicity. Curr Opin Immunol (2007) 19(3):348-53. doi:10.1016/j.coi. 2007.04.006

9. Madkaikar M, Shabrish S, Desai M. Current updates on classification, diagnosis and treatment of hemophagocytic lymphohistiocytosis (HLH). Indian J Pediatr (2016) 83(5):434-43. doi:10.1007/s12098-016-2037-y to conventional treatment even beyond early childhood. Moreover, it must be emphasized that insidious neurologic symptoms may represent the initial or sole presenting sign of FHL, even in the absence of any overt clinical manifestations of HLH. Considering that in FHL3 diagnostic delay may be fatal or result in irreversible neurologic sequelae, clinicians should be aware that unclassified neuroinflammatory diseases could be the sole initial sign of FHL. In this context, next-generation sequencing techniques and flow cytometric assays may play an important role in addressing the diagnosis. The precocious diagnosis of these conditions is pivotal to establish the best therapeutic approach.

\section{ETHICS STATEMENT}

The study was carried out in accordance with the Declaration of Helsinki and was approved by the institutional ethics committee of the University Federico II of Naples. Informed consent was obtained from all patients before the study.

\section{AUTHOR CONTRIBUTIONS}

CP, CC, GG, ML, and EC organized, collected, and analyzed the data and wrote the manuscript. PP, RR, MV, and LP followed up the patients, collected the data, and performed the experiments. CS performed whole exome sequencing; all authors reviewed and approved the manuscript.

10. Gray PE, Shadur B, Russell S, Mitchell R, Buckley M, Gallagher K, et al. Late-onset non-HLH presentations of growth arrest, inflammatory arachnoiditis, and severe infectious mononucleosis, in siblings with hypomorphic defects in UNC13D. Front Immunol (2017) 8:944. doi:10.3389/ fimmu.2017.00944

11. Cirillo E, Giardino G, Gallo V, D’Assante R, Grasso F, Romano R, et al. Severe combined immunodeficiency - an update. Ann N Y Acad Sci (2015) 1356:90-106. doi:10.1111/nyas.12849

12. Santoro A, Cannella S, Bossi G, Gallo F, Trizzino A, Pende D, et al. Novel Munc13-4 mutations in children and young adult patients with haemophagocytic lymphohistiocytosis. J Med Genet (2006) 43(12):953-60. doi:10.1136/jmg.2006.041863

13. Sieni E, Cetica V, Santoro A, Beutel K, Mastrodicasa E, Meeths M, et al. Genotype-phenotype study of familial haemophagocytic lymphohistiocytosis type 3. J Med Genet (2011) 48(5):343-52. doi:10.1136/ jmg.2010.085456

14. Henkes M, Finke J, Warnatz K, Ammann S, Stadt UZ, Janka G, et al. Late-onset hemophagocytic lymphohistiocytosis (HLH) in an adult female with Griscelli syndrome type 2 (GS2). Ann Hematol (2015) 94(6):1057-60. doi:10.1007/ s00277-014-2284-9

15. Kardas F, Patiroglu T, Unal E, Chiang SC, Bryceson YT, Kendirci M. Hemophagocytic syndrome in a 4-month-old infant with biotinidase deficiency. Pediatr Blood Cancer (2012) 59(1):191-3. doi:10.1002/pbc.23247

16. Sharpe LR, Ancliff P, Amrolia P, Gilmour KC, Vellodi A. Type II Gaucher disease manifesting as haemophagocytic lymphohistiocytosis. J Inherit Metab Dis (2009) 32(Suppl 1):S107-10. doi:10.1007/s10545-009-1091-2

17. Ravelli A, Minoia F, Davi S, Horne A, Bovis F, Pistorio A, et al. 2016 classification criteria for macrophage activation syndrome complicating systemic juvenile idiopathic arthritis: a European league against rheumatism/ American College of Rheumatology/Paediatric Rheumatology International Trials Organisation collaborative initiative. Arthritis Rheumatol (2016) 68(3):566-76. doi:10.1002/art.39332

18. Valentine G, Thomas TA, Nguyen T, Lai YC. Chronic granulomatous disease presenting as hemophagocytic lymphohistiocytosis: a case report. Pediatrics (2014) 134(6):e1727-30. doi:10.1542/peds.2014-2175 
19. Arico M, Bettinelli A, Maccario R, Clementi R, Bossi G, Danesino C. Hemophagocytic lymphohistiocytosis in a patient with deletion of 22q11.2. Am J Med Genet (1999) 87(4):329-30. doi:10.1002/(SICI)1096-8628(19991203) 87:4<329::AID-AJMG9>3.0.CO;2-M

20. Patiroglu T, Haluk Akar H, van den Burg M, Unal E, Akyildiz BN, Tekerek NU, et al. X-linked severe combined immunodeficiency due to a novel mutation complicated with hemophagocytic lymphohistiocytosis and presented with invagination: a case report. Eur J Microbiol Immunol (Bp) (2014) 4(3):174-6. doi:10.1556/eujmi-d-14-00019

21. Ozturk C, Sutcuoglu S, Atabay B, Berdeli A. X-linked agammaglobulinemia presenting with secondary hemophagocytic syndrome: a case report. Case Rep Med (2013) 2013:742795. doi:10.1155/2013/742795

22. Schultz KA, Neglia JP, Smith AR, Ochs HD, Torgerson TR, Kumar A. Familial hemophagocytic lymphohistiocytosis in two brothers with X-linked agammaglobulinemia. Pediatr Blood Cancer (2008) 51(2):293-5. doi:10.1002/ pbc. 21573

23. Pasic S, Micic D, Kuzmanovic M. Epstein-Barr virus-associated haemophagocytic lymphohistiocytosis in Wiskott-Aldrich syndrome. Acta Paediatr (2003) 92(7):859-61. doi:10.1111/j.1651-2227.2003.tb02548.x

24. Bode SF, Ammann S, Al-Herz W, Bataneant M, Dvorak CC, Gehring S, et al. The syndrome of hemophagocytic lymphohistiocytosis in primary immunodeficiencies: implications for differential diagnosis and pathogenesis. Haematologica (2015) 100(7):978-88. doi:10.3324/haematol.2014.121608

25. Ishii E. Hemophagocytic lymphohistiocytosis in children: pathogenesis and treatment. Front Pediatr (2016) 4:47. doi:10.3389/fped.2016.00047

26. Sieni E, Cetica V, Piccin A, Gherlinzoni F, Sasso FC, Rabusin M, et al. Familial hemophagocytic lymphohistiocytosis may present during adulthood: clinical and genetic features of a small series. PLoS One (2012) 7(9):e44649. doi:10.1371/journal.pone.0044649

27. Palterer B, Brugnolo F, Sieni E, Barilaro A, Parronchi P. Neuromyelitis optica, atypical hemophagocytic lymphohistiocytosis and heterozygous perforin A91V mutation. J Neuroimmunol (2017) 311:10-3. doi:10.1016/j. jneuroim.2017.08.003

28. Picard C, Al-Herz W, Bousfiha A, Casanova JL, Chatila T, Conley ME, et al. Primary immunodeficiency diseases: an update on the classification from the international union of immunological societies expert committee for primary immunodeficiency 2015. J Clin Immunol (2015) 35(8):696-726. doi:10.1007/ s10875-015-0201-1

29. Massaad MJ, Zhou J, Tsuchimoto D, Chou J, Jabara H, Janssen E, et al. Deficiency of base excision repair enzyme NEIL3 drives increased predisposition to autoimmunity. J Clin Invest (2016) 126(11):4219-36. doi:10.1172/jci85647

30. Tangye SG. Genetic cause of immune dysregulation - one gene or two? J Clin Invest (2016) 126(11):4065-7. doi:10.1172/jci90831

31. Casanova JL, Fieschi C, Zhang SY, Abel L. Revisiting human primary immunodeficiencies. J Intern Med (2008) 264(2):115-27. doi:10.1111/j.13652796.2008.01971.x

32. Gallo V, Dotta L, Giardino G, Cirillo E, Lougaris V, D’Assante R, et al. Diagnostics of primary immunodeficiencies through next-generation sequencing. Front Immunol (2016) 7:466. doi:10.3389/fimmu.2016.00466

33. Hoyos-Bachiloglu R, Chou J, Sodroski CN, Beano A, Bainter W, Angelova M, et al. A digenic human immunodeficiency characterized by IFNAR1 and IFNGR2 mutations. J Clin Invest (2017) 127:12. doi:10.1172/JCI93486

34. Rohr J, Beutel K, Maul-Pavicic A, Vraetz T, Thiel J, Warnatz K, et al. Atypical familial hemophagocytic lymphohistiocytosis due to mutations in UNC13D and STXBP2 overlaps with primary immunodeficiency diseases. Haematologica (2010) 95(12):2080-7. doi:10.3324/haematol.2010.029389

35. Jordan MB, Allen CE, Weitzman S, Filipovich AH, McClain KL. How I treat hemophagocytic lymphohistiocytosis. Blood (2011) 118(15):4041-52. doi:10.1182/blood-2011-03-278127

36. Seguin A, Galicier L, Boutboul D, Lemiale V, Azoulay E. Pulmonary involvement in patients with hemophagocytic lymphohistiocytosis. Chest (2016) 149(5):1294-301. doi:10.1016/j.chest.2015.11.004

37. Cashen K, Chu RL, Klein J, Rycus PT, Costello JM. Extracorporeal membrane oxygenation outcomes in children with hemophagocytic lymphohistiocytosis. Perfusion (2017) 32(2):151-6. doi:10.1177/0267659116667804

38. Trottestam H, Horne A, Arico M, Egeler RM, Filipovich AH, Gadner H, et al. Chemoimmunotherapy for hemophagocytic lymphohistiocytosis: long-term results of the HLH-94 treatment protocol. Blood (2011) 118(17):4577-84. doi:10.1182/blood-2011-06-356261
39. Kim MM, Yum MS, Choi HW, Ko TS, Im HJ, Seo JJ, et al. Central nervous system (CNS) involvement is a critical prognostic factor for hemophagocytic lymphohistiocytosis. Korean J Hematol (2012) 47(4):273-80. doi:10.5045/ kjh.2012.47.4.273

40. Haddad E, Sulis ML, Jabado N, Blanche S, Fischer A, Tardieu M. Frequency and severity of central nervous system lesions in hemophagocytic lymphohistiocytosis. Blood (1997) 89(3):794-800.

41. Zhang K, Filipovich AH, Johnson J, Marsh RA, Villanueva J. Hemophagocytic lymphohistiocytosis, familial. GeneReviews. Seattle: University of Washington (1993). Available from: https://www.ncbi.nlm.nih.gov/pubmed/20301617

42. Weisfeld-Adams JD, Frank Y, Havalad V, Hojsak JM, Posada R, Kaicker SM, et al. Diagnostic challenges in a child with familial hemophagocytic lymphohistiocytosis type 3 (FHLH3) presenting with fulminant neurological disease. Childs Nerv Syst (2009) 25(2):153-9. doi:10.1007/s00381-008-0744-z

43. Deiva K, Mahlaoui N, Beaudonnet F, de Saint Basile G, Caridade G, Moshous D, et al. CNS involvement at the onset of primary hemophagocytic lymphohistiocytosis. Neurology (2012) 78(15):1150-6. doi:10.1212/ WNL.0b013e31824f800a

44. Feldmann J, Menasche G, Callebaut I, Minard-Colin V, Bader-Meunier B, Le Clainche L, et al. Severe and progressive encephalitis as a presenting manifestation of a novel missense perforin mutation and impaired cytolytic activity. Blood (2005) 105(7):2658-63. doi:10.1182/blood-2004-09-3590

45. Shinoda J, Murase S, Takenaka K, Sakai N. Isolated central nervous system hemophagocytic lymphohistiocytosis: case report. Neurosurgery (2005) 56(1):187. doi:10.1227/01.NEU.0000146210.13318.E8

46. Moshous D, Feyen O, Lankisch P, Schwarz K, Schaper J, Schneider M, et al. Primary necrotizing lymphocytic central nervous system vasculitis due to perforin deficiency in a four-year-old girl. Arthritis Rheum (2007) 56(3):995-9. doi:10.1002/art.22442

47. Rostasy K, Kolb R, Pohl D, Mueller H, Fels C, Moers AV, et al. CNS disease as the main manifestation of hemophagocytic lymphohistiocytosis in two children. Neuropediatrics (2004) 35(1):45-9. doi:10.1055/s-2004-815791

48. Henter JI, Elinder G. Cerebromeningeal haemophagocytic lymphohistiocytosis. Lancet (1992) 339(8785):104-7. doi:10.1016/0140-6736(92)91008-V

49. Kieslich M, Vecchi M, Driever PH, Laverda AM, Schwabe D, Jacobi G. Acute encephalopathy as a primary manifestation of haemophagocytic lymphohistiocytosis. Dev Med Child Neurol (2001) 43(8):555-8. doi:10.1017/ S0012162201001001

50. Murphy C, Nanthapisal S, Gilmour K, Laurent S, D’Arco F, Hemingway C, et al. Progressive neurologic disorder: initial manifestation of hemophagocytic lymphohistiocytosis. Neurology (2016) 86(22):2109-11. doi:10.1212/ wnl.0000000000002729

51. Bryceson YT, Pende D, Maul-Pavicic A, Gilmour KC, Ufheil H, Vraetz T, et al. A prospective evaluation of degranulation assays in the rapid diagnosis of familial hemophagocytic syndromes. Blood (2012) 119(12):2754-63. doi:10.1182/blood-2011-08-374199

52. Mahlaoui N, Ouachee-Chardin M, de Saint Basile G, Neven B, Picard C, Blanche $S$, et al. Immunotherapy of familial hemophagocytic lymphohistiocytosis with antithymocyte globulins: a single-center retrospective report of 38 patients. Pediatrics (2007) 120(3):e622-8. doi:10.1542/peds.2006-3164

53. Marsh RA, Allen CE, McClain KL, Weinstein JL, Kanter J, Skiles J, et al. Salvage therapy of refractory hemophagocytic lymphohistiocytosis with alemtuzumab. Pediatr Blood Cancer (2013) 60(1):101-9. doi:10.1002/pbc.24188

54. Maschalidi S, Sepulveda FE, Garrigue A, Fischer A, de Saint Basile G. Therapeutic effect of JAK1/2 blockade on the manifestations of hemophagocytic lymphohistiocytosis in mice. Blood (2016) 128(1):60-71. doi:10.1182/ blood-2016-02-700013

Conflict of Interest Statement: The authors declare that the research was conducted in the absence of any commercial or financial relationships that could be construed as a potential conflict of interest.

Copyright (C) 2017 Giardino, De Luca, Cirillo, Palma, Romano, Valeriani, Papetti, Saunders, Cancrini and Pignata. This is an open-access article distributed under the terms of the Creative Commons Attribution License (CC BY). The use, distribution or reproduction in other forums is permitted, provided the original author(s) or licensor are credited and that the original publication in this journal is cited, in accordance with accepted academic practice. No use, distribution or reproduction is permitted which does not comply with these terms. 